\title{
Front Matter: Volume 8308
}

, "Front Matter: Volume 8308," Proc. SPIE 8308, Optoelectronic Materials and Devices VI, 830801 (4 January 2012); doi: 10.1117/12.921549

SPIE Event: SPIE/OSA/IEEE Asia Communications and Photonics, 2011, SPIE. Shanghai, China 


\title{
PROCEEDINGS OF SPIE
}

\section{Optoelectronic Materials and Devices VI}

\author{
Guang-Hua Duan \\ Editor
}

13-16 November 2011

Shanghai, China

\author{
Cosponsored by \\ SPIE \\ Optical Society of America \\ IEEE Photonics Society \\ Chinese Optical Society \\ China Institute of Communications \\ Local Organizing Committee \\ Shanghai University \\ Best Student Paper Sponsor \\ RSoft Design Group \\ Thorlabs, Inc. \\ Published by \\ SPIE \\ Optical Society of America \\ IEEE Photonics Society
}

Volume 8308 
The papers included in this volume were part of the technical conference cited on the cover and title page. Papers were selected and subject to review by the editors and conference program committee. Some conference presentations may not be available for publication. The papers published in these proceedings reflect the work and thoughts of the authors and are published herein as submitted. The publisher is not responsible for the validity of the information or for any outcomes resulting from reliance thereon.

Please use the following format to cite material from this book:

Author(s), "Title of Paper," in Optoelectronic Materials and Devices VI, edited by Guang-Hua Duan, Proceedings of SPIE-OSA-IEEE Asia Communications and Photonics, Vol. 8308 (SPIE, Bellingham, WA, 2011) Article CID Number.

ISSN 0277-786X

ISBN 9780819489562

Published by

SPIE

P.O. Box 10, Bellingham, Washington 98227-0010 USA

Telephone +1 3606763290 (Pacific Time) · Fax +1 3606471445

SPIE.org

Optical Society of America

2010 Massachusetts Ave., N.W., Washington, D.C., 20036 USA

Telephone +1 2022238130 (Eastern Time) • Fax +1 2022231096

OSA.org

IEEE Photonics Society

445 Hoes Lane, Piscataway, New Jersey, 08855 USA

Telephone +1 7325628434 (Eastern Time) • Fax +1 7325628434

IEEE.org

Copyright (C) 2011, Society of Photo-Optical Instrumentation Engineers, Optical Society of America, and IEEE Photonics Society.

Copying of material in this book for internal or personal use, or for the internal or personal use of specific clients, beyond the fair use provisions granted by the U.S. Copyright Law is authorized by SPIE subject to payment of copying fees. The Transactional Reporting Service base fee for this volume is $\$ 18.00$ per article (or portion thereof), which should be paid directly to the Copyright Clearance Center (CCC), 222 Rosewood Drive, Danvers, MA 01923. Payment may also be made electronically through CCC Online at copyright.com. Other copying for republication, resale, advertising or promotion, or any form of systematic or multiple reproduction of any material in this book is prohibited except with permission in writing from the publisher. The CCC fee code is $0277-786 \times / 11 / \$ 18.00$.

Printed in the United States of America.

Publication of record for individual papers is online in the SPIE Digital Library.

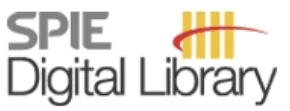

SPIEDigitalLibrary.org

Paper Numbering: Proceedings of SPIE follow an e-First publication model, with papers published first online and then in print and on CD-ROM. Papers are published as they are submitted and meet publication criteria. A unique, consistent, permanent citation identifier (CID) number is assigned to each article at the time of the first publication. Utilization of CIDs allows articles to be fully citable as soon as they are published online, and connects the same identifier to all online, print, and electronic versions of the publication. SPIE uses a six-digit CID article numbering system in which:

- The first four digits correspond to the SPIE volume number.

- The last two digits indicate publication order within the volume using a Base 36 numbering system

employing both numerals and letters. These two-number sets start with 00, 01, 02, 03, 04, 05, 06, 07, 08, 09, 0A, OB ... OZ, followed by 10-1Z, 20-2Z, etc.

The CID number appears on each page of the manuscript. The complete citation is used on the first page, and an abbreviated version on subsequent pages. Numbers in the index correspond to the last two digits of the six-digit CID number. 


\title{
Contents
}

\author{
xi Symposium Committees \\ xiii Conference Committee
}

\section{SESSION 1 NONLINEAR AND SWITCHING DEVICES I}

830804 The Brillouin gain and experiment performance based on stimulated Brillouin scattering slow light [8308-04]

H. Zhou, R. Zhang, K. Zhong, Beijing Univ. of Posts and Telecommunications (China)

830805 Heterodyne method monitoring broadband slow light based on stimulated Brillouin scattering [8308-05]

K. Zhong, H. Zhou, C. Cao, R. Zhang, Beijing Univ. of Posts and Telecommunications (China)

\section{SESSION 2 BEST STUDENT PAPER SESSION}

830807 All-optical edge detector for NRZ signal using a SOA-MZI [8308-07]

Q. Weng, G. Wang, X. Yang, W. Hu, Shanghai Jiao Tong Univ. (China)

8308 0A Transmission characteristics of a novel grating assisted microring [8308-10]

F. Lou, Royal Institute of Technology (Sweden); X. Zhang, Wuhan National Lab. for Optoelectronics (China) and Huazhong Univ. of Science and Technology (China); L. Wosinski, Royal Institute of Technology (Sweden) and Joint Research Ctr. of Photonics of the Royal Institute of Technology and Zhejiang Univ. (China)

8308 OB Ultracompact variable optical attenuator based on photonic crystal waveguide [8308-11] Q. Zhao, K. Cui, Y. Huang, Tsinghua Univ. (China)

8308 0C Compact surface wave polarization splitter based on the metallic-dielectric-air waveguide [8308-12]

F. LU, G. Li, Z. Wang, K. Li, A. Xu, Peking Univ. (China)

\section{SESSION 3 NONLINEAR AND SWITCHING DEVICES II}

8308 OE All-optical $\mathbf{4 0}$ Gbit/s data format conversion between RZ and NRZ using a fiber delay interferometer and a single SOA [8308-14]

F. Wang, Chongqing Univ. of Technology (China); E. XU, Nanjing Univ. of Posts and Telecommunications (China); Y. YU, Y. Zhang, Wuhan National Lab. for Optoelectronics (China) and Huazhong Univ. of Science and Technology (China)

8308 OF Patterning effect mitigation using complementary data for NRZ wavelength conversion with a SOA-MZI [8308-15]

G. Wang, X. Yang, Q. Weng, W. Hu, Shanghai Jiao Tong Univ. (China) 
8308 OG Modulation instability of optical nonlinear media: a route to chaos [8308-17]

M. A. Sharif, Urmia Univ. of Technology (Iran, Islamic Republic of)

\section{SESSION 4 GE AND III-V LASERS}

8308 0J A novel tunable semiconductor laser based on a sampled grating reflector and an interleaved sampled grating reflector [8308-20]

H. Wang, J. Zhao, Y. YU, Wuhan National Lab. for Optoelectronics (China)

\section{SESSION 5 NANOSTRUCTURED MATERIALS AND QUANTUM DOTS I}

$8308 \mathrm{OL}$ Theoretical estimation of optical absorption coefficient inside an InAs/InGaAs semiconductor quantum dot [8308-23]

S. Behjati Ardakani, H. Kaatuzian, Amirkabir Univ. of Technology (Iran, Islamic Republic of)

8308 OM A $1550 \mathrm{~nm}$ PbS semiconductor quantum dots fiber amplifier based on $\mathrm{SiO}_{2}$ sol-gel method [8308-24]

X. Sun, C. Li, L. Xie, X. Liu, Y. Dong, Shanghai Univ. (China)

8308 ON Control of mode $Q$ factor and direction-emission by metal confinement for defected circular microresonators [8308-25]

Q.-F. Yao, J.-D. Lin, Y.-D. Yang, Y.-Z. Huang, Institute of Semiconductors (China)

830800 Transport electron through a quantum wire by side-attached asymmetric quantum-dot rings [8308-26]

A. Rostami, Univ. of Tabriz (Iran, Islamic Republic of); S. Zabihi, H. Rasooli S., S. K. Seyyedi, Islamic Azad Univ. (Iran, Islamic Republic of)

\section{SESSION 6 PICS}

8308 OR Quantifying direct DQPSK receiver with integrated photodiode array by assessing an adapted common-mode rejection ratio [8308-29]

J. Wang, M. Lavermann, C. Zawadzki, W. Brinker, Z. Zhang, D. de Felipe, N. Keil, N. Grote, M. Schell, Fraunhofer-Institut für Nachrichtentechnik, Heinrich-Hertz-Institut (Germany)

\section{SESSION 7 PHOTONIC CRYSTALS}

$8308 \mathrm{OV} \quad \mathrm{K}_{\mathrm{z}}$ component dependence of photonic band gap in two-dimensional photonic crystal [8308-33]

X. Guo, L. Han, G. Yuan, Z. Yu, Y. Liu, P. Lu, Beijing Univ. of Posts and Telecommunications (China)

8308 OW Wideband slow light in one-dimensional grating waveguide [8308-34]

C. Bao, Wuhan National Lab. for Optoelectronics (China); J. Hou, Wuhan National Lab. for Optoelectronics (China) and South-Central Univ. for Nationalities (China); H. Wu, Wuhan National Lab. for Optoelectronics (China) and Nanchang Hangkong Univ. (China); D. Gao, $X$. Zhang, Wuhan National Lab. for Optoelectronics (China) 
8308 OY Enhanced optical transmission through a metallic slit covered with a nanostrip and surrounded by corrugations [8308-37]

G. Li, F. LU, Z. Meng, A. Xu, Peking Univ. (China)

$83080 Z$ Gain-assisted propagation of surface plasmon polaritons using electrically pumped quantum wells as active medium [8308-38]

T. Mei, South China Normal Univ. (China); Y. Li, Nanyang Technological Univ. (Singapore): H. Zhang, N. Zhu, South China Normal Univ. (China); D. H. Zhang, Nanyang Technological Univ. (Singapore); J. Teng, A*STAR Institute of Materials Research and Engineering (Singapore)

830810 Switchable polarization-sensitive surface plasmon resonance of highly stable gold nanorods liquid crystals composites [8308-39]

Q. Liu, Zhejiang Univ. (China) and Univ. of Colorado at Boulder (United States); J. Qian,

F. Cai, Zhejiang Univ. (China); I. I. Smalyukh, Univ. of Colorado at Boulder (United States);

S. He, Zhejiang Univ. (China) and Royal Institute of Technology (Sweden)

830811 Novel subwavelength optical signal access via a plasmonic concentrator and a dielectric microring [8308-40]

K. Li, G. Li, Z. Wang, F. Lu, A. Xu, Peking Univ. (China)

\section{SESSION 9 NANOSTRUCTURED MATERIALS AND QUANTUM DOTS II}

830812 Hybrid III-V/Si active microcavities based on photonic crystals (Invited Paper) [8308-41] P. Viktorovitch, C. Sciancalepore, Institut des Nanotechnologies de Lyon, CNRS, Univ. de Lyon (France); B. Ben Bakir, CEA-LETI Minatec (France); X. Letartre, Institut des Nanotechnologies de Lyon, CNRS, Univ. de Lyon (France); N. Olivier, CEA-LETI Minatec (France); C. Seassal, Institut des Nanotechnologies de Lyon, CNRS, Univ. de Lyon (France); D. Bordel, CEA-LETI Minatec (France); P. Rojo-Romeo, P. Regreny, Institut des Nanotechnologies de Lyon, CNRS, Univ. de Lyon (France)

830813 Optical properties of GaN/AIN quantum dots under intense laser field [8308-42] L. Zhang, Z. Yu, W. Yao, Y. Liu, H. Feng, Beijing Univ. of Posts and Telecommunications (China)

830815 A PbS quantum dot polymer optical waveguide amplifier [8308-44] L. Lan, F. Pang, X. Sun, T. Wang, Shanghai Univ. (China)

830816 A dual-band UV and IR quantum cascade photodetector [8308-45] A. Rostami, S. Khosravi, H. Rasooli Saghai, Univ. of Tabriz (Iran, Islamic Republic of)

\section{SESSION 10 OPTICAL INTERCONNECTS AND ACCESS DEVICES}

830818 High-speed 850 and $980 \mathrm{~nm}$ VCSELs for high-performance computing applications (Invited Paper) [8308-47]

A. Mutig, P. Moser, Technische Univ. Berlin (Germany); J. A. Lott, VI Systems GmbH (Germany); P. Wolf, W. Hofmann, Technische Univ. Berlin (Germany); N. N. Ledentsov, VI Systems GmbH (Germany); D. Bimberg, Technische Univ. Berlin (Germany) 
$830819850 \mathrm{~nm}$ optical components for $25 \mathrm{~Gb} / \mathrm{s}$ optical fiber data communication links over $100 \mathrm{~m}$ at $85^{\circ} \mathrm{C}$ [8308-48]

S. A. Blokhin, Connector Optics LLC (Russian Federation) and A. F. Ioffe Physico-Technical Institute (Russian Federation); J. A. Lott, N. N. Ledentsov, VI Systems GmbH (Germany); L. Ya. Karachinsky, A. G. Kuzmenkov, I. I. Novikov, N. A. Maleev, Connector Optics LLC (Russian Federation) and A. F. Ioffe Physico-Technical Institute (Russian Federation); G. Fiol, D. Bimberg, Technische Univ. Berlin (Germany)

SESSION 11 NANOSTRUCTURED MATERIALS AND QUANTUM DOTS III

8308 1D Quantum dot and star like lead sulfide for infrared radiation detection [8308-52]

M. Dolatyari, S. Miri, H. Shekari, A. Bakhtiari, A. Rostami, Univ. of Tabriz (Iran, Islamic Republic of)

SESSION 12 PASSIVE INTEGRATED DEVICES

8308 IE Optical routers for photonic networks-on-chip (Invited Paper) [8308-53]

L. Yang, R. Ji, L. Zhang, Y. Tian, J. Ding, H. Chen, Y. Lu, P. Zhou, W. Zhu, Institute of Semiconductors (China)

8308 IF Ultrashort and ultrabroadband silicon polarization beam splitter based on a bent directional coupler [8308-54]

D. Dai, Univ. of California, Santa Barbara (United States) and Zhejiang Univ. (China);

J. E. Bowers, Univ. of California, Santa Barbara (United States)

8308 IG Novel silicon-on-insulator grating couplers based on CMOS poly-silicon gate layer [8308-55]

C. Qiu, Shanghai Institute of Microsystem and Information Technology (China), Grace Semiconductor Manufacturing Corp. (China), and Graduate Univ. of Chinese Academy of Sciences (China); Z. Sheng, Shanghai Institute of Microsystem and Information Technology (China); L. Li, A. Pang, Grace Semiconductor Manufacturing Corp. (China); A. Wu, J. Du,

J. Chen, X. Wang, F. Gan, Shanghai Institute of Microsystem and Information Technology (China); S. Zou, Shanghai Institute of Microsystem and Information Technology (China) and Grace Semiconductor Manufacturing Corp. (China)

$8308 \mathrm{1H}$ An analysis of electro-optic measurement of electric fields using Jones matrix formulation [8308-56]

H. Ismail, A. Nirmalathas, E. Skafidas, The Univ. of Melbourne (Australia)

830811 Investigation of the use of rotating linearly polarized light for characterizing $\mathrm{SiO}_{2}$ thin film on Si substrate [8308-57]

C. Pawong, R. Chitaree, C. Soankwan, Mahidol Univ. (Thailand)

\section{SESSION 13 SILICON PHOTONICS I}

$83081 \mathrm{~K} \quad 1 \times 3$ optical drop splitter in a rod-type silicon photonic crystal [8308-59]

D. Zhuang, Fujian Normal Univ. (China); X. Chen, Minjiang Univ. (China); J. Li, Fujian Normal Univ. (China); G. Lin, Minjiang Univ. (China); Z. Qiang, Y. Qiu, H. Li, Fujian Normal Univ. (China) 
$83081 \mathrm{~L}$ CMOS-compatible thermal compensator based on a modified Mach-Zender interferometer [8308-60]

Q. Long, H. Yi, X. Wang, Peking Univ. (China); Z. Zhou, Peking Univ. (China) and Georgia Institute of Technology (United States)

\section{SESSION 14 SILICON PHOTONICS II}

$83081 \mathrm{M} \quad$ High-speed silicon optical modulators (Invited Paper) [8308-61]

G. T. Reed, D. Thomson, F. Y. Gardes, N. G. Emerson, Univ. of Surrey (United Kingdom); J.-M. Fédéli, CEA-LETI Minatec (France)

8308 IP Low-voltage, high-extinction ratio carrier-depletion Mach-Zehnder silicon optical modulator [8308-89]

J. Ding, H. Chen, R. Ji, L. Yang, Y. Tian, L. Zhang, W. Zhu, Y. Lu, R. Min, P. Zhou, Institute of Semiconductors (China)

8308 1R Broad gain injectorless quantum-cascade lasers with low threshold emitting around $8.6 \mu \mathrm{m}$ [8308-91]

H. Li, S. Katz, G. Boehm, M.-C. Amann, Walter Schottky Institut (Germany)

\section{POSTER SESSION}

8308 is Optical logic operation for AND gate based on planar photonic crystal circuit [8308-16] K.-Y. Lee, China Univ. of Science and Technology (Taiwan, China); Y.-P. Yang, I.-C. Yang, National Central Univ. (Taiwan, China); Y.-L. Tsai, H.-F. Liao, Y.-J. Lin, W.-Y. Lee, China Univ. of Science and Technology; Y.-T. Tsai, National Central Univ. (Taiwan, China)

$83081 \mathrm{~T} \quad$ Three-wavelength multiplexer/demultiplexer based on photonic crystal ring resonator and cavities [8308-35]

J. Zhang, X.-M. XU, L.-J. He, Nanchang Univ. (China)

$83081 \mathrm{U} \quad$ Highly efficient channel drop filter based on photonic crystal one-way waveguide [8308-64] H. Ren, H. Wen, Y. Qin, S. Guo, Zhejiang Univ. of Technology (China); W. Hu, C. Jiang, Y. Jin, Shanghai Jiao Tong Univ. (China)

$83081 \mathrm{~V}$ Intracavity frequency doubling of PPKTP-based optical parametric oscillator [8308-65] Q. Li, J. Tian, Beijing Univ. of Technology (China); X. Zhang, Y. Song, L. Wang, Beijing Univ. of Technology (United States)

8308 IW Dual-depletion-region lumped electroabsorption modulator for low capacitance and expected high bandwidth [8308-66]

Y. Shao, L. Zhao, H. Yu, J. Pan, B. Wang, H. Zhu, W. Wang, Institute of Semiconductors (China) 
$83081 \mathrm{X}$ Polyatomic photonic crystal waveguides with semi-slow light and tailored dispersion properties [8308-69]

D. Wang, Lanzhou Univ. of Technology (China) and Beijing Univ. of Posts and Telecommunications (China); J. Zhang, Beijing Univ. of Posts and Telecommunications (China); L. Yuan, J. Lei, Lanzhou Univ. of Technology (China); S. Chen, J. Han, Y. Zhao, Beijing Univ. of Posts and Telecommunications (China)

8308 IY Microscopic study on the carrier distribution in optoelectronic device structures: experiment and modeling [8308-70]

W. Huang, H. Xia, S. Wang, H. Deng, P. Wei, Shanghai Institute of Technical Physics (China); L. Li, F. Liu, Institute of Semiconductors (China); Z. Li, T. Li, Shanghai Institute of Technical Physics (China)

$83081 Z$ Modeling of white light emitting diodes (WLED) based on GaN/InGaN multi quantum dots structure [8308-71]

A. Rostami, B. Rostami Dogolsara, H. Rasooli Saghai, M. Leilaeioun, Univ. of Tabriz (Iran, Islamic Republic of)

830820 Zinc oxide nanoplates for ultraviolet radiation detection [8308-72] M. Dolatyari, E. Amini, H. Shekari, A. Bakhtiari, A. Rostami, Univ. of Tabriz (Iran, Islamic Republic of)

830821 Ultrahigh-speed all-optical wavelength conversion for PolSK signal based on parallel dual-pump FWM in SOA [8308-73]

P. Li, W. Shi, Nanjing Univ. of Posts and Telecommunications (China); D. Huang, Wuhan National Lab. for Optoelectronics (China)

830822 Multiwavelength converter exploiting cross-gain modulation in SFRL [8308-74] T. Pan, P. Li, S. Huang, Z. Zhao, Nanjing Univ. of Posts and Telecommunications (China)

830824 Hybrid-integrated coherent receiver using silica-based planar lightwave circuit technology [8308-76]

J.-H. Kim, J.-S. Choe, K.-S. Choi, C.-J. Youn, D.-J Kim, S.-H. Jang, Y.-H. Kwon, E.-S. Nam,

Electronics and Telecommunications Research Institute (Korea, Republic of)

830826 Preparation of gold colloid and its surface-enhanced Raman scattering properties [8308-78] L. Hu, Z. Chen, N. Chen, W. Zhang, H. Zhu, S. Liu, T. Wang, Shanghai Univ. (China)

830827 Multichannel analog-to-digital converters based on current mirrors for the optical systems [8308-79]

V. G. Krasilenko, Open International Univ. of Human Development (Ukraine); A. I. Nikolskyy, M. A. Nikolska, Vinnitsa National Technical Univ. (Ukraine); R. F. Lobodzinska, Open International Univ. of Human Development (Ukraine)

830829 Experimental research on $10 \mathrm{~Gb} / \mathrm{s}$ all-optical logic gates with return-to-zero data in high nonlinear fiber [8308-81]

W. Wang, J. YU, Tianjin Univ. (China); B. Han, Tianjin Univ. (China) and Shanxi Datong Univ. (China); J. Guo, J. Luo, J. Wang, Y. Liu, E. Yang, Tianjin Univ. (China) 
8308 2A 40GHz optoelectronic oscillator with low-frequency optical and microwave devices [8308-82]

B. Han, Tianjin Univ. (China) and Shanxi Datong Univ. (China); J. Yu, W. Wang, J. Guo, J. Wang, E. Yang, Tianjin Univ. (China)

8308 2B The effect of growth temperature on InAs quantum dots grown by MOCVD [8308-83] T. Li, X. Guo, Q. Wang, P. Wang, Z. Jia, X. Ren, Y. Huang, S. Cai, Beijing Univ. of Posts and Telecommunications (China)

8308 2C Effect of boron on the surface and optical properties for (B)InAs/GaAs self-assembled quantum dots grown by MOCVD [8308-84]

P. Wang, Q. Wang, X. Guo, Z. Jia, T. Li, X. Ren, S. Cai, Beijing Univ. of Posts and Telecommunications (China)

8308 2D Analysis and optimization of a dual-absorption RCE photodetector for high-speed applications [8308-85]

D. Li, Y. Huang, X. Duan, W. Wang, X. Ren, Beijing Univ. of Posts and Telecommunications (China)

$83082 \mathrm{E}$ Design and analysis of resonant cavity enhanced photodetector by using InP-based concentric circular subwavelength grating [8308-86]

T. Wang, Y. Huang, X. Duan, Y. Shang, W. Wang, X. Ren, Beijing Univ. of Posts and Telecommunications (China)

$83082 \mathrm{~F}$ Study of the dynamics of the nonlinear polarization rotation in a semiconductor optical amplifier [8308-87]

O. Pérez-Cortés, Ctr. de Investigación Científica y de Educación Superior de Ensenada (Mexico); A. Albores-Mejia, Eindhoven Univ. of Technology (Netherlands); H. Soto-Ortiz, Ctr. de Investigación Científica y de Educación Superior de Ensenada (Mexico)

83082 G Analysis of SHB and thermal characteristics in PC-VCSEL considering photonic crystal parameters [8308-88]

G. Haghighat, V. Ahmadi, S. Pahlavan, Tarbiat Modares Univ. (Iran, Islamic Republic of)

Author Index 
Downloaded From: https://www.spiedigitallibrary.org/conference-proceedings-of-spie on 26 Apr 2023

Terms of Use: https://www.spiedigitallibrary.org/terms-of-use 


\title{
Symposium Committees
}

\author{
Honorary General Chairs
}

Tingye Li, AT\&T Laboratories (retired) (United States)

Bingkun Zhou, Tsinghua University (China)

General Chairs

Jian-Jun He, Zhejiang University (China)

Ken-ichi Kitayama, Osaka University (Japan)

Xingde Li, Johns Hopkins University (United States)

Technical Program Chairs

Perry Shum, Nanyang Technological University (Singapore)

Yikai Su, Shanghai Jiao Tong University (China)

Arthur Chiou, National Yang-Ming University (Taiwan, China)

Local Organizing Committee

Yunqi Liu, Shanghai University (China)

Ronghui Qu, Shanghai Institute of Optics and Fine Mechanics (China)

Tingyun Wang, Shanghai University (China)

Xiaobei Zhang, Shanghai University (China)

Steering Committee Chairs

Ming-Jun Li, Corning USA (United States)

John Zyskind, Oclaro, Inc. (United States)

Steering Committee Members

Sailing He, Zheijang University (China)

Peter Kaiser, Telcordia Technologies (retired)

Connie Chang-Hasnain, University of California, Berkeley (United

States)

Chongcheng Fan, Tsinghua University (China)

Mao Qian, WRI-Fiberhome (China)

Xiaomin Ren, Bejing University of Posts \& Telecommunications (China) 
Downloaded From: https://www.spiedigitallibrary.org/conference-proceedings-of-spie on 26 Apr 2023

Terms of Use: https://www.spiedigitallibrary.org/terms-of-use 


\title{
Conference Committee
}

\author{
Conference Chair
}

Guang-Hua Duan, III-V Laboratory (France)

Conference Cochairs

Yidong Huang, Tsinghua University (China)

Yoshiaki Nakano, The University of Tokyo (Japan)

Liming Zhang, Alcatel-Lucent Bell Laboratories (United States)

Program Committee

Sheng-Lung L. Huang, National Taiwan University (Taiwan, China)

Wei-Ping Huang, McMaster University (Canada)

Yong-Zhen Huang, Institute of Semiconductors (China)

Akihiko Kasukawa, The Furukawa Electric Company, Ltd. (Japan)

Christian Lerminiaux, Université de Technologie Troyes (France)

Lih-Yuan Lin, University of Washington (United States)

Ting Mei, South China Normal University (China)

Graham Trevor Reed, University of Surrey (United Kingdom)

Haisheng Rong, Intel Corporation (United States)

Jung H. Shin, KAIST (Korea, Republic of)

Junqiang Sun, Huazhong University of Science and Technology (China)

Kiyoto Takahata, NTT Photonics Laboratory (Japan)

Dries Van Thourhout, Universiteit Gent (Belgium)

Valery I. Tolstikhin, OneChip Photonics Inc. (Canada)

Shih-Yuan Wang, Hewlett-Packard Laboratories (United States)

Zhiping Zhou, Peking University (China) 
Downloaded From: https://www.spiedigitallibrary.org/conference-proceedings-of-spie on 26 Apr 2023

Terms of Use: https://www.spiedigitallibrary.org/terms-of-use 